\title{
Socio-Technical Theory
}

\section{and Job Design in Libraries}

\begin{abstract}
Under the influence of socio-technical theory, recent job satisfaction research has focused upon the areas of (1) the work itself, (2) the individual versus the organization, and (3) job design. Successful job design appears to depend upon finding satisfactory solutions to accommodate an organization's needs, its technology, and the desires and demands of the employed individuals. The creation of autonomous jobs at all levels of responsibility are seen as the key to a successful relationship between these three key components of the socio-technical system.
\end{abstract}

S called an ecological focus that provides meaningful insight into the structure of organizations and job content. Socio-technical theory considers organizations to be purposive and postulates that organizations interact with their surrounding social and technological environment across permeable boundaries. Technology is considered a significant variable that interacts jointly with social and personal variables to form the system that carries out the purposes of an organization. It considers the individuals within the organization to be purposive, whole human beings who reflect and shape the values of society in interaction with technology as they seek to satisfy their own as well as the organization's needs. Applications of socio-technical concepts appear to develop satisfying, yet economically efficient jobs. ${ }^{1}$

Past studies of job satisfaction have been and are still being carried out mostly by psychologists or sociologists. According to Davis, most of these studies are tainted by major flaws. Job satisfaction is treated as an end in itself and reveals little about causeand-effect relationships. ${ }^{2}$ Psychologists have

Klaus Musmann is head acquisitions librarian, Los Angeles County Law Library, and a doctoral student in the School of Library Science, University of Southern California. not examined variables that are influenced by technology and have ignored the interaction between social and technical systems. Furthermore, most such studies have failed to examine the job itself. Psychological studies, which have recommended job enlargement as a means to increase job satisfaction, have examined the relationship between repetitive work and monotony and between task length and satisfaction, but they have never examined the relevant technology largely responsible for many of the dehumanizing tasks found in industrial work situations.

More recent job satisfaction research, under the influence of socio-technical theory, has focused upon three distinct areas of research, namely (1) on the work itself, (2) on the individual versus the organization, and (3) on job design.

This paper will focus upon these three areas and will attempt to explore some of the problem areas of job design for library employees. Herzberg, Paul, Likert, and Lawler have written extensively on the relationship of motivation and satisfaction to the intrinsic, substantive contents of jobs. ${ }^{3}$ In the area of the individual versus the organization, attention has been focused upon the interaction between technology and social organization in shaping the roles of individuals. Models of jobs and organizations have been designed that are motivating and 
satisfying to individuals and groups and suitable to an organization and its technology.

Here the researchers have been concerned about the impact of the changing technology and the social environment and personal values in conflict with organizational concepts that are outmoded for our time. Writings on job design have focused upon responsible, autonomous job behavior as the key to a successful interrelationship among individuals, organizations, and technology.

Autonomous behavior is defined as selfregulation of work content and structure within the job, self-evaluation of performance, and participation in the setting of job goals and objectives. Responsible job behavior includes acceptance by the individual or group for the cycle of activities to complete the services and accountability for the quantity and quality of the output. It also includes recognition of the interdependence of an individual on others for completion of the cycle of activities. ${ }^{4}$

Successful job design seems to depend upon finding satisfactory solutions to bridge the needs of the organization and its technology and the desires and demands of the employed individuals. At the same time, the organization must make sure that the objectives of its subunits are relevant to an organization's overall goal objectives and that the organization remains adaptive to its environment. $^{5}$

\section{LIBRARY TECHNOLOGY AND THE ENVIRONMENT}

Few, if any, of these concepts have found their way into the field of library literature, although the evolution of socio-technical systems theory has been taking place over the past fifteen years.

One of the few writers in our field has been Beverly P. Lynch, who recently published two articles in College \& Research Libraries. ${ }^{6}$ In her first article she attempted to delineate the environment of the academic library, and in the second one she employed Perrow's model of organizational technology to compare the work of fifteen different departments in three academic libraries. Her articles did not focus directly upon job design and satisfaction in libraries, but she did touch upon important aspects that are ultimately related to successful job design. Lynch adapted Perrow's model of technology to the environment of the library in the following manner: ${ }^{7}$

1. Materials technology, i.e., the nature of the raw material entering a department. The essential characteristic was the perception of the material's predictability or unpredictability.

2. Operations technology, i.e., the techniques employed to change the raw material into a finished product. The essential characteristic was whether a department's operation was routine or nonroutine.

3. Knowledge technology, i.e., the knowledge required by the library's staff to convert the raw materials into the finished product. The essential characteristic was whether a particular department's knowledge was sufficient to complete the tasks.

Lynch found that the nature of the work performed in the various departments (reference, catalog, serials, acquisitions, circulation, and searching) was very similar regardless of a department's functions. In terms of predictability of the material, the routineness of operations, and the knowledge necessary to perform the required tasks, relatively minor differences emerged between departments. The final conclusions of her study were that the technologies of all departments consisted of predictable events, routine operations, and relatively low knowledge requirements. ${ }^{8}$

But a word of caution is in order here. Lynch's model of library technology was a measurement of attitudes about work rather than an evaluation of the work itself. Furthermore, her questionnaires were distributed to all full-time employees, including both professional and clerical staff members. This factor alone would certainly introduce a high degree of bias toward routine operations and low knowledge requirements because of the large number of clerical employees engaged in such operations.

In her article on the environment of the academic library, Beverly Lynch states that librarians generally think of organizational change in the library as being internally generated. She writes that "it is frequently said that if the managerial style of the library director would change or if the staff 
had broader participation in the decision making, the library's performance would change." ${ }^{9}$ of course, environmental factors, i.e., external events, could greatly influence the decision-making power within the library and may well reduce the decisionmaking autonomy of the library itself. Lynch goes on to say that it may be difficult to determine whether organizational change is initiated by internal or external antecedents, but the main point is that librarians must be aware of external as well as internal events that are shaping the library's organizational structure. ${ }^{10}$

It is important to note that complex, heterogeneous, and unstable environments impose greater constraints and contingencies upon an institution than environments that are simple, homogeneous, and stable. ${ }^{11}$ Departments with uncertain environments rely less on formal rules and procedures, have fewer job performance reviews, and are less formal overall than departments with stable environments. Such findings are, of course, essential for any serious study of job satisfaction.

The stability of our environment has to be determined before we can begin to design jobs in library organizations that are satisfactory not only to the individuals employed in libraries but also to the aims of the library itself. Unfortunately, little is known about the impact of the environment upon the library's internal structure. However, Beverly Lynch has at least made a start in analyzing some of the underlying factors essential to applying the principles of socio-technical theories to libraries.

\section{THE STIGMATIZATION OF THE NONPROFESSIONAL}

Lynch found that the technology of the library consists of predictable events and of routine operations and that it requires relatively low knowledge to perform the required tasks in most departments of an academic library. If we accept her findings as accurate, we have an immediate area of potential for job dissatisfaction due to the nature of the work itself.

Unfortunately, Lynch did not make a distinction between the work performed by professional and clerical employees since she was primarily interested in the technol- ogy of departments and their alleged differences. But the area of professional versus clerical work contains another potential for job dissatisfaction for both clerical and professional library employees in addition to the problem area of the work itself. Most theories regarding work motivation have held that nonprofessionals are not concerned with self-actualization but are merely interested in extrinsic factors, i.e., pay, so that they may be able to purchase satisfaction away from their jobs. It has been assumed that "lower-order needs are barely met (i.e., pay) and that therefore higherorder, intrinsic factors (i.e., self-actualization) cannot be met." 12

Self-actualization is said to be important because it is supposed to improve the efficiency and effectiveness of employees in organizations by meeting their personal needs. However, a substantial body of literature exists that refutes such claims. Jerome Seliger quotes the work of David Sirota, who tested such claims and found no correlation between ego fulfillment and personal or organizational effectiveness. ${ }^{13}$ But selfactualization exists as a normative and popular value in the society at large and must therefore be treated in an organization as if it were a real need.

Self-actualization, freedom, independence, and specialized knowledge are associated with professional standing in our society. Our society appears to value professionalism to a very high degree, and most people want to be called professionals. In a society that values professionalism, individuals who occupy nonprofessional positions are stigmatized. ${ }^{14}$ Although nonprofessionals could enter a work situation imbued with values similar to those held by professionals, the nonprofessionals' work experience will soon teach them that their "careers" are not as important as those of the professionals in the same work situation, and attitudes toward their work may be affected adversely. ${ }^{15}$ If nonprofessionals enter the organization in expectation of job satisfaction and status and find low status and boring, routine work instead, then it seems reasonable to expect that they will become alienated either psychologically or behaviorally in regard to the organization's objectives. ${ }^{16}$ 
We know that librarians have a higher status than the clerical support staff and that the latter find themselves stigmatized by the low status of their occupation. In fact, individuals in higher-status occupations have a vested interest in encouraging stigmatization because of their own insecurity regarding their occupational status. It is possible that librarians encourage such stigmatization because of the fear that their own status might be threatened by the low status clerical employees as "peers" in the hierarchy of the organization. It has been stated that such low status transference "seems to be a very general anxiety, felt most strongly perhaps by just those groups which have most recently achieved some degree of status."17

\section{Professionalism AND ORganIZATIONS}

Professionalism is seen by some students of organizations as the successor to bureaucracy. A professional's loyalties are to the profession and go beyond the confines of an organization's rules and regulations. The professional has the personal freedom to be independent of the organization. Ronald Corwin, in a study of conflict in nursing roles, has stated that a professional is concerned with an expanding body of knowledge that may change the accepted practice in an organization. In contrast, a bureaucrat is concerned with preserving the routine elements inherent in an institution. Corwin found that those individuals who were considered professional had more role conflict in regard to their status within the organization than those who did not have a professional degree. ${ }^{18}$

Another study found that a basic conflict exists between the salaried professionals and the bureaucracies that employ them. Peter Blau and Richard Scott, in their book Formal Organizations, viewed the professional's expertise and the bureaucrat's discipline as alternative methods of coping with uncertainty. The professional's loyalty to the profession is a dilemma that "affects wider and wider circles as the number of people subject to these conflicting control mechanisms grows." 19 More and more professionals work in bureaucratic organizations, and the operations of bureaucracies are becoming increasingly professionalized.
Seliger speaks of a built-in conflict between the values and obligations associated with professionalism and organization structure and cites as evidence the organization of professional social workers in task groupings that "are more consistent with orientation toward the organization." ${ }^{20}$ They are compelled to meet more of the organization's goals than the goals of their profession. He states that, as a general principle, specialist groupings are associated with professional orientation while task groupings are not. These findings appear to have a direct bearing on the organizational structure of libraries. Certainly, the recent reorganization at Columbia University is a step toward a specialist grouping and away from the traditional organization of large academic libraries.

\section{REWARDS AND MOTIVATION}

If we now turn away from the area of the individual versus the organization and toward job design, we will have to examine Maslow's hierarchy of needs. His theory has been widely accepted in the area of job motivation together with Herzberg's motivation-hygiene theory. Maslow categorized various human needs into five basic groups, which he labeled as follows:

1. The need for self-actualization

2. The need for self- and group-esteem

3. The needs for love and belongingness

4. The need for safety

5 . The physiological needs ${ }^{21}$

In this paper we are primarily concerned with the need for self-actualization and the needs for self- and group-esteem. According to Maslow, these are the higher-order needs that can be perceived only after partial fulfillment of the lower-order needs. Selfactualization is thought of as being a realization of every person's full potential. This state is thought of as making life more meaningful and assumes that the selfactualized person continually seeks such a psychological state. No empirical support for such a theory exists. ${ }^{22}$ But it appears that Maslow's hierarchy has found nearly universal acceptance.

Herzberg's theory, too, has found wide acceptance. It states that motivation is dependent upon two different components: hygiene factors and motivation factors. Job 
dissatisfaction ensues, according to Herzberg, when hygiene factors deteriorate to a level below which the employee considers acceptable. Hygiene factors do not motivate the employee, but they do eliminate job dissatisfaction. Motivation factors are those factors that satisfy and motivate the individual, but they have little or no effect on job dissatisfaction itself. Herzberg has been criticized extensively for the many methodological errors in his study, and his hypothesis has made poor showings in retesting situations. ${ }^{23}$

Herzberg argues that job factors that define the job context are of little importance to the employee. Ullrich, on the other hand, argues convincingly that Herzberg is wrong in his findings. As in the case with salaries, there is usually no direct relationship between the efforts individuals invest in their jobs and the quality of the working conditions they receive in return. No matter how hard individuals work, their working conditions will remain virtually unchanged, as will their job security and their status within the organization.

Even if improvements in these conditions were aspired to by an individual, the lack of environmental potential would render motivation under such conditions unrealistic. Where promotional opportunities offer the potential for improved working conditions and status, the increase in need satisfaction may be so small that they are deemed without practical value. In Ullrich's words:

the reader is undoubtedly familiar with cases in which improvements in working conditions earned by a promotion consists of having a coat tree, a larger desk, or some other trivial addition brought to the individual's place of work. How much harder is one going to work to earn a coat tree?24

Financial incentives provided by most employers fall into a similar category. The salaries paid by most employers serve more to encourage employees to establish and to maintain employment rather than encourage greater motivation on the part of the employees. Most employers establish salary schedules that limit the salary to each given type of job. Usually salaries conform to those of other employers in similar loca- tions. Usually employers pay neither more nor less than their competitors. ${ }^{25}$

It is clear that under such a system salaries will not be an incentive to individual productivity. Regardless of whether an individual works harder than anyone else, the salary of this employee will remain the same. Even pay raises are considered by Ullrich to be of marginal importance in motivating employees since most pay raises are not substantial enough to have any real impact on an individual's salary. Furthermore, pay raises are granted, not because of individual effort, but are given equally to everyone as a cost-of-living increment or as an automatic step increase for seniority. Goal-seeking behavior, i.e., motivation, is uncalled for under such conditions. If money is to be used for employee motivation, financial rewards must be substantial. Where individuals aspire toward greater incomes, money can be used to bring about goal-seeking behavior. ${ }^{26}$

In summary, then, we can state that where rewards are provided by the formal work environment, which are perceived by employees as being average or better, satiation may occur. Ullrich states, and here he is in partial agreement with Maslow, that "needs can be fulfilled in the short run to levels at which further goal-seeking behavior ceases because aspirations cease to rise." $27 \mathrm{He}$ feels that certain forms of technology, work methods, etc., limit an employee's ability to seek fulfillment for higher-order needs and thereby discourage goal-seeking behavior. Under such conditions, individuals will favor behavior that supports the status quo, and the organization itself will move toward homeostasis and will become resistant to change. ${ }^{28}$

The continued existence of good working conditions does not depend upon the daily activities of an employee to attain the objectives of the organization. The rewards of good working conditions are automatically granted as long as the employee agrees to maintain the status quo. The formation of motivation requires the formation of an action goal. The recognition or creation of an unfulfilled employee aspiration is the beginning of initiating employee motivation.

Achievement, recognition, responsibility, and the work itself can be thought of as 
providing fulfillment of Maslow's higherorder needs for an individual. These need fulfillments can be obtained in proportion to the employee's activity level. Achievement is a transitory experience, and individuals must maintain a high degree of performance to continually increase their feelings of achievement. But if employees are to achieve fulfillment of their higher-order needs in the work environment, they will have to be given substantial control over their own tasks. The individual employee would gain authority and would experience at the same time an increased commitment to the organization's objectives. ${ }^{29}$

\section{SPONTANEITY AND WORK}

Our conception of work has undergone dramatic changes over the past thirty years. Work may still be a burdensome imposition while leisure is a world of freedom and spontaneity. Apparently, people aspire to enjoy their work as they do their leisure. It has been frequently noted that pleasurable experiences possess a degree of spontaneity that is lacking in most work situations. Similarly, pleasurable experiences lose some of their value when their spontaneity is lost. Someone's hobby may well lose its enjoyment when it becomes a full-time job. This implies that the work of an individual may contain the potential for need fulfillment, but work may "impose temporal limitations on activities which cause these activities to be undertaken past the point at which aspired levels of fulfillment have been obtained."30

The spontaneity of pleasurable activities is determined by two unique characteristics. Such activities are structured in a way that allows the individual to move toward or away from the activity and pleasurable activities that appear to exist as alternatives to one another. Having satisfied one desire, one may undertake a second activity at one's own choice. These prerequisites to spontaneity are lacking in most work environments. Usually, one has neither the option to cease working nor the opportunity to find alternative work activities. Most of our work in libraries tends to be structured in a way that does not permit spontaneity.

The successful pursuit of need fulfillment depends on individuals' ability to pursue their needs as they experience them, but also on the availability of aspired need fulfillment. Timing is one of the most important and frequently overlooked factors in the design of jobs. This is precisely the reason why academic work is so attractive because of the freedom given to the individual in designing both job content and temporal arrangements for task completion. Such decision making should be left to individual employees. It would increase the enjoyment of their work. It should be stressed that employees enjoy their labor because it provides aspired increments in their rate of need fulfillment. This is not the same as saying that individuals work because they enjoy their work. It merely means that high morale may follow successful, goal-seeking behavior. $^{31}$

\section{INNOVATIVE LIBRARY REORGANIZATION}

Recently, two studies were published that seem to forebode well for the future of job design in librarianship. One is the Booz, Allen \& Hamilton study of Columbia University's libraries, ${ }^{32}$ and the other one is Ricking and Booth's Personnel Utilization in Libraries. ${ }^{33}$ Both studies, although prepared for quite different purposes, illustrate innovative concepts in library management.

As mentioned earlier, Columbia University's reorganization is a step forward toward professionalization of librarianship, at least at the senior level. This library was reorganized into a resources group, a services group, and a support group. The resources group comprises primarily senior professionals who are responsible for planning and carrying out collection development and preservation, in-depth reference and research assistance, classroom instruction, and original cataloging.

All of the foregoing services are thoroughly professional in nature and would certainly score quite differently on Beverly Lynch's technology scale. But most important of all, at least as far as job satisfaction for professional librarians is concerned, they would free the professional from the stultifying routine of functional, assembly-line type of production work and would fully utilize the professional's talents that are underutilized in the more traditional types of organizations in research libraries. 
The library is also committed to an individualized career development program for the staff. According to the proposal, "highly individualized" programs would be prepared for each staff member by top management with the active participation of all librarians. ${ }^{34}$ The study also includes staff development plans for specialists and for the clerical staff. The plan specifies help and encouragement to develop individual career interests and to fulfill individual career goals. Expanded levels of professional capabilities are thought of as benefiting the library by building a more dynamic staff.

Professional competency, in addition to administrative responsibility, as demonstrated through individual initiative, was singled out as "the central criterion for a successful career." ${ }^{35}$ Professional staff evaluation would be based upon employees' performances of current responsibilities as well as on their progress toward long-term professional growth and development. Evaluation of supervisors' capacities to motivate the staff toward the organization's objectives and their own professional motivation and attitudes are also proposed by this study.

Again, all of these proposals center upon the development of the staff and the professionalization of librarianship. Unfortunately, the study is silent on the actual design of satisfying jobs for either professional or clerical employees. Position classifications and general job descriptions are given, although the actual tasks that are to be performed by each employee are omitted.

The Booz study did not consider the variable of technology and the impact it has on the social system of the library, nor did it spell out the amount of control individuals would have over the content of their own jobs. Of course, job design and employee motivation were not of central importance to the Booz study. But it is surprising that the authors failed to approach the library as a socio-technical system, especially in view of the sweeping changes they proposed for the organizational structure of the library. We know that technical changes have a direct bearing not only on the tasks that are to be performed and on the work-role relationship but that they also affect the absolute and relative rewards as well as the status of different groups within an organiza- tion. The authors' extensive bibliography did not reveal a single reference to sociotechnical research findings, although they did consider Columbia University's libraries as a system and were concerned about the library's responsiveness to its environment.

\section{TASK ANALYSIS}

The objectives of Ricking and Booth, on the other hand, were to get away from position classification and to reveal the nature of the work itself in order to determine in an objective way a basis for job design through task analysis. In contrast to most other studies on library job descriptions, which are usually descriptions of general and rather vague duties, their task analysis is specific and spells out in detail the exact functions and duties of librarians, technicians, and clerical workers for various library subsystems.

They have taken a systems approach and considered the entire spectrum of the library's goals and objectives, its programs, and the tasks needed to accomplish its purpose. It is beyond the scope of this paper to consider the many additional aspects of their approach.

In their opinion, task analysis and job design cannot be approached unless one considers the organizational goals and objectives as well as the motivation of the employees who perform the actual work. In a quote from Chris Argyris' Personality and Organization, they point out that

Theoretically, this means that healthy adults will tend to obtain optimum personality expression while at work if they are provided with jobs which permit them to be more active than passive; more independent than dependent; to have longer rather than shorter time perspectives; to occupy higher positions than their peers; to have control over their world; and to express many of their deeper, more important abilities. ${ }^{36}$

Furthermore, they agree that traditional organization theory is incongruent to the development of healthy human beings and that rigidly traditional work environments lead to "psychological failure," particularly as one goes down the line of command and "jobs become more and more mechanized." 37

In contrast with the traditional processcentered approach, they state that the worker-centered approach is more suitable 
to today's society inasmuch as it emphasizes the participation of the employee in decision making and gives meaning to the work situation. Job enlargement and job rotation are additional approaches to relieve the monotony of routine jobs. A number of libraries have assigned professional staff to subject areas where they have complete control from acquisition through cataloging and reference service within a given subject area. They conclude their survey with Davis' job-centered approach, which states that no job can be adequately designed without considering the variables of the processes, the worker, and the organization as well as the variables arising from their interaction. $^{38}$

Ricking and Booth recommend some form of participatory management for all functions they describe in their model. Closer harmony between the employees and the organization will be the result of such participation. In addition, they express the hope that an employee's competency and personal job satisfaction will continue to grow over the years. To encourage such a development, they suggest that libraries adopt the following recommendations:

(1) Creative job design, based on the goals of the individual as well as those of the organization; (2) involvement of the individual in determining the organization's purpose, goals, objectives, and programs; and (3) a flexible career movement within the agency as programs change and individuals develop. $^{39}$

\section{CONCLUSIONS}

The Ricking and Booth study is an excellent and innovative approach to personnel utilization in libraries. But as was the case with the earlier discussed studies, the problem of creative job design and employee motivation on all levels is never fully explored. But their task listing provides us with a solid and detailed description of the actual library tasks. With this information at our disposal we should be able to design jobs that meet the requirements of sociotechnical theory. Of course, a listing of tasks is not enough.

We will have to plan for the compatibility between the values of our culture and the value of our libraries, the autonomy of the individual and the control imposed by our institutions, the demands of the work system itself and the responses employees are equipped to give. We will have to plan for a minimum of rigidity in the application of technology upon job content and structure. Modern organizational planning should develop minimal critical tasks necessary to achieve the goals of our organizations instead of imposing detailed specifications and restrictions on jobs.

Libraries are in an excellent position to offer potential for self-actualization and fulfillment of employees' needs at both the professional and the support level because library work is socially significant and can easily be restructured to achieve individual and organizational compatibility. ${ }^{40}$

\section{REFERENCES}

1. Louis E. Davis, Job Satisfaction Research: The Post-Industrial View (Los Angeles: University of California, Institute of Industrial Relations, 1971), p. $185-86$.

2. Ibid., p.181.

3. See the detailed bibliographical survey in Davis, Job Satisfaction, p.188.

4. Ibid., p. 190.

5. Ibid., p.191.

6. Beverly P. Lynch, "The Academic Library and Its Environment," College \& Research Libraries 35:126-32 (March 1974), and "A Framework for a Comparative Analysis of Library Work," College \& Research Libraries 35:432-43 (Nov. 1974).

7. Lynch, "Framework," p.440.
8. Lynch, “Framework," p.441.

9. Lynch, “Academic Library,” p.128.

10. Lynch, “Academic Library," p.128.

11. Lynch, "Academic Library," p.130.

12. Jerome S. Seliger, The Effects of Position Classification on Need Satisfaction and Work Attitudes (Dissertation, Univ. of Southern California, 1974).

13. Ibid., p.5.

14. Ibid., p. 13.

15. Ibid., p. 17-18.

16. Ibid., p. 37 .

17. Ibid., p.24-25.

18. Ibid., p. 10.

19. Ibid., p.42.

20. Ibid., p. 240. 
21. Robert A. Ullrich, A Theoretical Model of Human Behavior in Organizations (Morristown, N.J.: General Learning Press, 1972), p.7.

22. Ibid., p. 9 .

23. Ibid., p. 18.

24. Ibid., p. 189.

25. Ibid., p.186.

26. Ibid., p.188.

27. Ibid., p. 190.

28. Ibid., p. 191.

29. Ibid., p.199.

30. Ibid., p.196.

31. Ibid., p. 196.

32. Booz, Allen \& Hamilton, Inc., Organization and Staffing of the Libraries of Columbia
University (Westport, Conn.: Redgrave, 1973).

33. Myrl Ricking and Robert E. Booth, Personnel Utilization in Libraries (Chicago: American Library Assn., 1974).

34. Booz, Organization and Staffing, p.154-55.

35. Ibid., p. 156.

36. Ricking, Personnel Utilization, p.26.

37. Ibid., p. 27.

38. Ibid., p. 29.

39. Ibid., p.31.

40. Kenneth H. Plate and Elizabeth W. Stone, "Factors Affecting Librarian's Job Satisfaction: A Report of Two Studies," Library Quarterly 49:99 (April 1974). 